\title{
THE EFFECT OF CERAMIC FIBERS ON THE IMMUNE SYSTEM
}

\author{
Jana Tulinska ${ }^{\mathrm{a}}$, Miroslava Kuricova ${ }^{\mathrm{a}}$, Aurelia Liskova ${ }^{\mathrm{a}}$, Zuzana Kovacikova ${ }^{\mathrm{b}}$, Elizabeth Tatrai ${ }^{\mathrm{c}}$ \\ a Laboratory of Immunotoxicology, Department of Immunology and Immunotoxicology, Research Base of Slovak Medical \\ University - Institute of Preventive and Clinical Medicine, Limbova 14, Bratislava, Slovakia \\ ${ }^{b}$ Laboratory of Biochemistry, Department of Bioactive Material, Research Base of Slovak Medical University - Institute \\ of Preventive and Clinical Medicine \\ c Department of Pathology, National Institute of Occupational Health, Budapest, Hungary \\ e-mail: jana.tulinska@szu.sk
}

Received: June 10, 2005; Accepted: September 25, 2005

Keywords: Ceramic fibers/Immune system/Immunotoxicity/Lymhpocytes/Phagocytosis/Immunosuppression

Male Sprague-Dawley rats were treated by intratracheal instillation with $1 \mathrm{mg} /$ animal of refractory ceramic fibers. Intratracheal exposure to ceramic fibers led to significant changes of immune response. Results of proliferative activity of spleen lymphocytes showed significantly decreased proliferative activity of T-cells in response to mitogens phytohemagglutinin and concanavalin A in animals given ceramic fibers in comparison with control rats. Similarly, T-dependent B-cell response to pokeweed mitogen was significantly suppressed. Spontaneous proliferative activity of lymphocytes in non-stimulated spleen cell cultures did not differ in exposed and control rats. No significant changes were found among groups in percentage of phagocytic blood polymorphonuclear leukocytes and percentage of cells with respiratory burst.

\section{INTRODUCTION}

The evidence for adverse health effects following exposure to asbestos has prompted a drastic reduction in the use of asbestos, resulting in the increased use of substitutes composed of both naturally occurring and synthetic materials which are thought to have lower toxicity.

Ceramic fibers are important component of insulation wools. Biological effects of refractory ceramic fibers depend among other factors on size, durability of fibers in the organism, their surface properties and chemical composition of fibers. Generally, published studies indicate, that ceramic fibers activate pulmonary macrophages and they are characterized by a moderate fibrotic activity, but detailed information related to the immunotoxicity and immunomodulatory ability of ceramic fibers is still limited. Our study was aimed to assess the effect of ceramic fibers on selected parameters of systemic cellular immune response in Sprague-Dawley rats.

\section{MATERIAL AND METHODS}

Male Sprague-Dawley rats (ISASZEG, Hungary) with starting weight of 200-220 g were treated by intratracheal instillation with $1 \mathrm{mg}$ of refractory ceramic fibers $(1 \mathrm{mg} /$ animal, Carbolane Fibres, Saint-Gobain, Ceramiques Industrielles, Nanterre, France). After one month, the animals were killed in deep anaesthesia with Narcotane (Narcotane, Leciva, Praha). The blood samples were taken from abdominal aorta by lithium-heparin syringes.
The spleen was aseptically removed and placed into RPMI medium. The materials were kept at $4{ }^{\circ} \mathrm{C}$.

In vitro lymphocyte proliferative assay

Spleen cells were rinsed out by syringe with needle into complete RPMI cultivate medium with heparin. Cell suspension was centrifuged (1200 rpm/5min) and resuspended in RPMI with 10\% FCS. Splenocytes were cultured with mitogens concanavalin A (Con A, Sigma) from Canavalia ensiformis, phytohemagglutinin (PHA, Sigma) from Phaseolus vulgaris and pokeweed mitogen (PWM, Sigma) from Phytolacca americana in final concentrations: Con A $5 \mu \mathrm{g} / \mathrm{ml}$, PHA $25 \mu \mathrm{g} / \mathrm{ml}$, PWM $2.5 \mu \mathrm{g} /$ $\mathrm{ml}$ in microtitrate plates at $37^{\circ} \mathrm{C}$ for $72 \mathrm{~h}$. One $\mu \mathrm{Ci}$ (in $25 \mu \mathrm{l}$ medium) of $\left[{ }^{3} \mathrm{H}\right]$-thymidine (Amersham) per well was added $24 \mathrm{~h}$ prior to cell harvesting onto glass filter paper using the Cell Harvester (Dynatech). $\left[{ }^{3} \mathrm{H}\right]$-thymidine incorporation was determined by liquid scintillation counting. Results were expressed as disintegrations per minute $(\mathrm{dpm})$ /culture.

\section{Phagocytic activity and respiratory burst flow cytometry assay}

Preparation of SPA particles: Lyophilized FITC-labeled Staphylococcus aureus particles (SPA) (Molecular Probes) were properly resuspended in sterile PBS using ultrasound. The corresponding amount of opsonized reagent was added into tube and incubated $1 \mathrm{~h}$ at $37^{\circ} \mathrm{C}$. After incubation particles were left on shaker for $45 \mathrm{~min}$ at room temperature and then four times washed in PBS (centrifugation at $3000 \mathrm{rpm}$ at $4^{\circ} \mathrm{C}$ for 10 minutes). After 


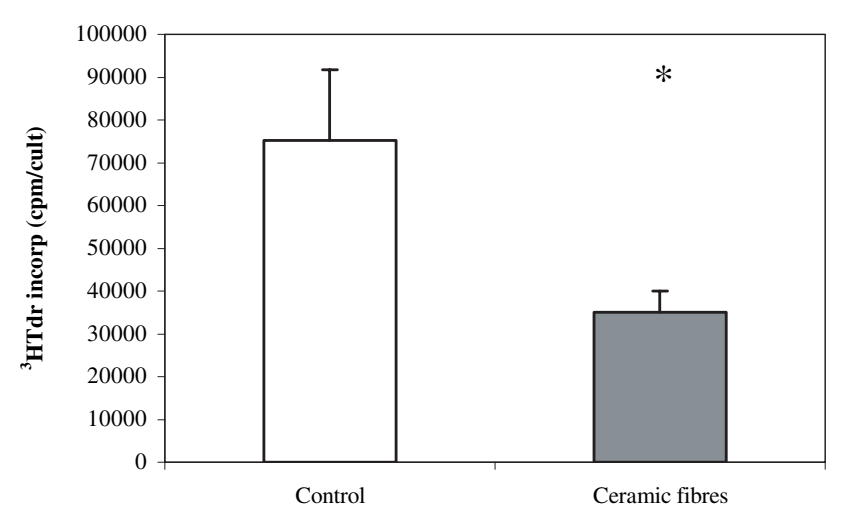

Fig. 1. Proliferative activity of spleen T-lymphocytes in vitro stimulated with concanavalin A. Male Sprague-Dawley rats were administered by intratracheal instillation with $1 \mathrm{mg}$ refractory ceramic fibers (1mg/animal) and killed after one month.

$\mathrm{Y}$ axis shows incorporation of [3H]-thymidine into replicating cells. Results are expressed as disintegrations per minute per culture.

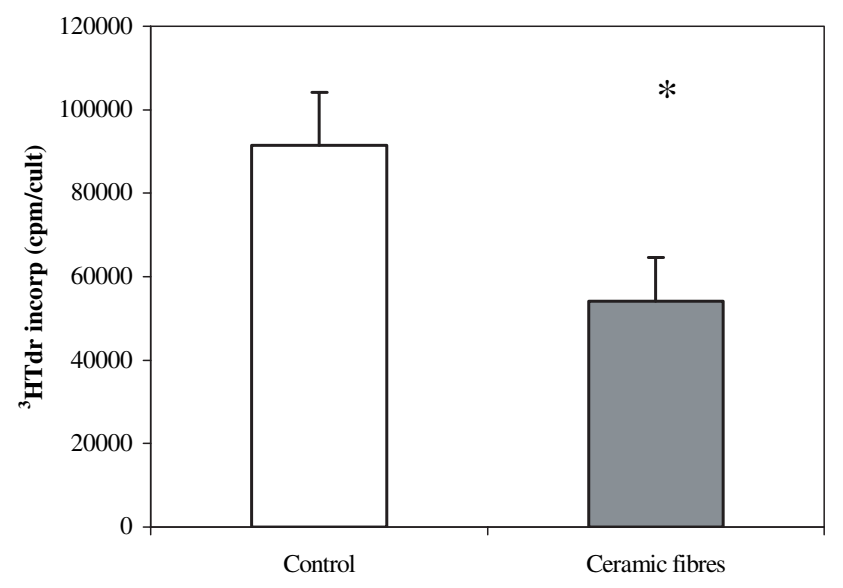

Fig. 3. Proliferative activity of spleen T-dependent B-lymphocytes in vitro stimulated with pokeweed mitogen. Male Sprague-Dawley rats were administered by intratracheal instillation with $1 \mathrm{mg}$ refractory ceramic fibers (1mg/animal) and killed after one month. $\mathrm{Y}$ axis shows incorporation of [3H]-thymidine into replicating cells. Results are expressed as disintegrations per minute per culture.

washing, final concentration of SPA particles was measured using flow cytometry.

Phagocytic activity and respiratory burst test: $30 \mu \mathrm{l}$ of whole Li-heparinized blood and $10 \mu \mathrm{l}$ of working solution of hydroxyethidine ( $0.1 \mathrm{mM} \mathrm{HE}$ ) were used for determination of phagocytic activity and respiratory burst of cells. The control and test tubes were used for each animal sample and set up in duplicates. Tubes were incubated $15 \mathrm{~min}$ at $37^{\circ} \mathrm{C}$. Calculated number of $1.4 \times 10^{6}$ of particles in volume of $2-5 \mu \mathrm{l}$ was added only into each test tube. All samples were again incubated at $37^{\circ} \mathrm{C}$ for $15 \mathrm{~min}$. After

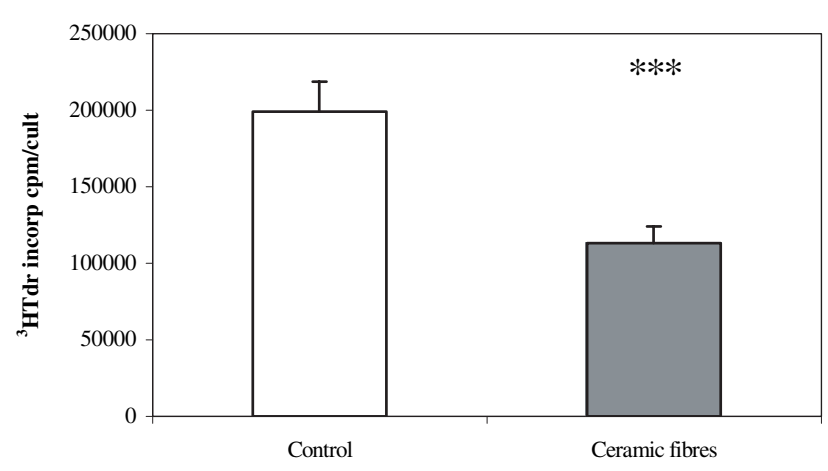

Fig. 2. Proliferative activity of spleen T-lymphocytes in vitro stimulated with phytohemmaglutinin. Male Sprague-Dawley rats were administered by intratracheal instillation with $1 \mathrm{mg}$ refractory ceramic fibers (1mg/animal) and killed after one month.

$\mathrm{Y}$ axis shows incorporation of [3H]-thymidine into replicating cells. Results are expressed as disintegrations per minute per culture.

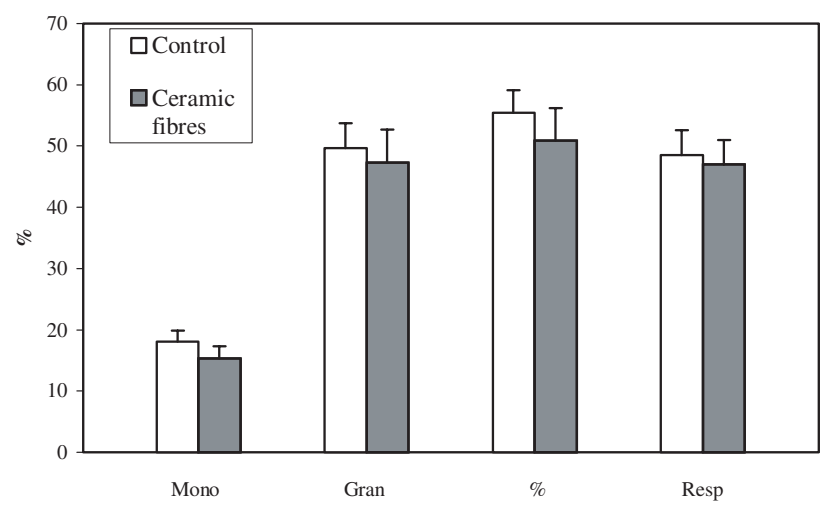

Fig. 4. Phagocytic activity and respiratory burst of peripheral blood cells in male Sprague-Dawley rats administered with $1 \mathrm{mg}$ refractory ceramic fibres (1 mg/animal).

Mono - Percentage of phagocytic monocytes, Gran - Percentage of phagocytic granulocytes, $\%$ - Percentage of phagocytic cells with respiratory burst,

Resp - Total percentage of cells with respiratory burst

incubation, $700 \mu$ l of cold lysing solution was added. Into control tubes the same volume of SPA particles was added as previously described. All tubes were left on ice. After $10 \mathrm{~min}$ of lysis process the measurement of phagocytic activity and respiratory burst test was performed using flow cytometry. 


\section{RESULTS AND DISCUSSION}

Intratracheal administration of ceramic fibers to Sprague-Dawley rats resulted in significant changes in immune system of exposed animals. Results of proliferative activity of spleen lymhocytes are depicted in Figures 1-3. DNA synthesis in spleen lymphocytes in vitro stimulated with phytohemagglutinin was significantly decreased in comparison with cultures derived from control rats. Similarly, proliferative activity of splenocytes in cultures stimulated with concanavalin A showed significant suppression in animals given ceramic fibers. Function of lymphocytes was impaired also in in vitro cultures stimulated with concanavalin A. Spontaneous proliferation of lymphocytes measured as incorporation of ${ }^{3} \mathrm{H}$-thymidine into non-stimulated spleen cells did not differ in exposed and control rats.

Phagocytic activity of peripheral blood cells was assessed by ability to ingest bacteria Staphylococcus aureus. No significant changes were found among groups in percentage of phagocytic blood polymorphonuclear leukocytes (PMN) and percentage of cells with respiratory burst (Fig. 4).

Our data of suppressed proliferative activity of T-lymphocytes and decreased T-dependent B-cell response indicate fiber-induced changes in systemic immune response. Hypothesis that inhaled particles or fibers can exert adverse effects outside of the lung is supported by several studies. Although, most of findings refer to systemic effect of particles, similar influence of fibers can be assumed. For example ultrafine particles were found to decrease the number of blood PMNs and increase the intracellular oxidation of a fluorescent dye (DCFD) in blood PMNs (ref. ${ }^{1}$ ). Diesel exhaust particles and carbon black particles had significant adjuvant effect on the local immune-mediated inflammatory response in the draining popliteal lymph node and on the systemic specific IgE response to model allergen ovalbumin in BALB/c mice ${ }^{2}$. Recent data of van Eeden ${ }^{3}$ showed the effects of particulate air pollution on bone-marrow stimulation in animals. Acute exposure to ambient particles accelerates the transit of polymorphonuclear leukocytes (PMN) through the marrow whereas chronic exposure expands the size of the bone marrow pool of PMN.

A communication between the fiber-induced processes in the pulmonary compartment and peripheral tissues can be mediated by: 1) leakage of reactive oxygen species and stress-induced cytokines directly into the peripheral blood, 2) (pre)activation of peripheral blood leukocytes that can result in aberrant homing and activation of inflammatory cells in distant tissues, and 3) the liberation of proinflammatory mediators by leukocytes and/or stromal cells present in the pulmonary tissues ${ }^{4}$.

\section{ACKNOWLEDGEMENT}

We would like to express our gratitude to Viera Vachalkova, Helena Turazova and Maria Valentova for their excellent technical help. This work was supported by NKFP1/B-047/2004, OTKA 046733, ETT 154/2003-6.

\section{REFERENCES}

1. Elder AC, Gelein R, Azadniv M, Frampton M, Finkelstein J, Oberdorster G. (2004) Systemic effects of inhaled ultrafine particles in two compromised, aged rat strains. Inhal Toxicol 16 , 461-71.

2. Lovik M, Hogseth AK, Gaarder PI, Hagemann R, Eide I. (2003) Diesel exhaust particles and carbon black have adjuvant activity on the local lymph node response and systemic IgE production to ovalbumin. Eur Respir J 46, Suppl, 5s-13s.

3. van Eeden SF, Hogg JC. (2002) Systemic inflammatory response induced by particulate matter air pollution: the importance of bonemarrow stimulation. J Toxicol Environ Health A 65, 1597-613.

4. Oudijk EJ, Lammers JW, Koenderman L. (2003) Systemic inflammation in chronic obstructive pulmonary disease. Eur Respir J 46, Suppl, 5s-13s. 